Su, M., Young, B. and Gardner, L. (2016), "The continuous strength method for aluminium alloy design", Engineering Structures, 122: 338-348.

\title{
The Continuous Strength Method for the Design of Aluminium Alloy
}

\section{Structural Elements}

\author{
Mei-Ni Su${ }^{1}$, Ben Young ${ }^{2}$ and Leroy Gardner ${ }^{3}$
}

\begin{abstract}
Aluminium alloys are nonlinear metallic materials with rounded stress-strain curves that are not well represented by the simplified elastic-perfectly plastic material model used in most existing design specifications. Departing from current practice, the continuous strength method (CSM) is a recently developed design approach for aluminium alloy structures, which includes the beneficial influence of strain hardening. The CSM is a deformation-based method and employs a base curve to define the continuous relationship between cross-section slenderness and deformation capacity. This paper explains the background and the two key components of the CSM: (1) the base curve, which is extended herein such that the method covers both non-slender and slender sections and (2) the bi-linear (elastic, linear hardening) material model. Three international design specifications from America, Australia/New Zealand and Europe, as well as the CSM are compared with approximately 900 aluminium alloy experimental and numerical results. The CSM for indeterminate structures enables collapse loads beyond those determined from traditional plastic design through a systematic exploitation of strain hardening. Reliability analyses have been carried out to assess the reliability level of different design methods according to both the American Institute of Steel
\end{abstract}


Construction (AISC) and European Standard (EN 1990) approaches. Finally, worked examples of the CSM for aluminium alloy stub columns and continuous beams are illustrated in this paper.

KEY WORDS: Aluminium alloys; Base curve; Columns; Continuous beams; Continuous strength method (CSM); Reliability analyses; Simply supported beams; Strain hardening; Structural design

\footnotetext{
${ }^{1}$ Assistant professor, Dept. of Civil Engineering, Shenzhen University, Shenzhen, China

${ }^{2}$ Professor, Dept. of Civil Engineering, The Univ. of Hong Kong, Pokfulam Road, Hong Kong. E-mail: young@hku.hk

${ }^{3}$ Professor, Dept. of Civil and Environmental Engineering, Imperial College London, London SW7 2AZ, UK. E-mail: leroy.gardner@imperial.ac.uk
}

\section{Introduction}

Aluminium alloys are being increasingly used in building facades, roof systems, moving bridges and structures situated in humid environments. For efficient and economical structural design, it is important to recognize the key characteristics of aluminium alloys and to fully utilise them in design. Aluminium alloys exhibit nonlinear material stress-strain curves with significant strain hardening and reasonable ductility. This study focuses on strain hardening of aluminium alloys at the cross-sectional level and moment redistribution in indeterminate structures at the global system level, neither of which are fully exploited in current aluminium alloy specifications.

The continuous strength method (CSM) was originally developed for stainless steel and carbon steel materials, and is a deformation-based design framework that allows for the beneficial influence of strain hardening. A series of studies [1-5] have been conducted to 
develop and improve the CSM in the past decade. Owing to the general similarity of structural behaviour between stainless steel and aluminium alloys, the authors investigated the feasibility of applying the CSM to aluminium alloy structures. The key components of the CSM for aluminium alloy structures are described in this paper, including the base curve and the bi-linear (elastic, linear hardening) material model. Furthermore, for indeterminate structures, the CSM considers the degree of rotation at each plastic hinge, leading to different cross-section capacities at different hinges. The CSM is then used to predict the capacities of aluminium alloy stub columns, simply supported beams as well as continuous beams of a range of cross-section shapes - I-sections, channels, angles and square and rectangular hollow sections (SHS/RHS) with and without internal cross stiffeners. The data set used for comparisons is made up of a collection of test results and numerical simulations from the literature.

There are a number of established aluminium alloy structural design specifications currently available, such as the Aluminum Design Manual [6], the Australian/New Zealand Standard [7] and Eurocode 9 [8]. These specifications provide design rules for a range of structural components and applications though, in some areas, including the capacity of aluminium alloy compression and flexural members, design provisions are often conservative [9-17]. In the case of Class 1 and Class 2 cross-sections [8], this conservatism is largely attributed to the lack of account for strain hardening and moment redistribution. This is recognized in Annex F of EC9 [8] for stub columns and simply supported beams as well as in Annex H of EC9 [8] for continuous beams, where alternative design methods are provided to consider strain hardening and global plastic analysis. 


\section{Continuous strength method (CSM) for aluminium alloys}

\subsection{General concepts}

The continuous strength method (CSM) is a deformation-based design framework that allows for the beneficial influence of strain hardening. The method is focussed primarily on nonslender sections where local buckling occurs after yielding and hence where additional strength from strain hardening can be exploited [9, 10, 12]. For slender sections, local buckling failure occurs prior to yielding and hence strain hardening is generally not encountered. However, for some non-doubly symmetric slender sections in bending, even if the extreme fiber strain in compression is less than the yield strain, strains significantly beyond the yield strain can be experienced in tension; these strain are accompanied by strain hardening, which can therefore be exploited in design. Examples of such cases include angle sections, channel sections in minor axis bending and T-sections in major axis bending. In light of this, the CSM base curve for non-slender sections $[9,10,12]$ is extended to also cover slender sections in this study, thus enabling the CSM to be applied to the full spectrum of cross-section slenderness.

The two main features of the CSM are (1) a base curve defining the level of strain that a cross-section can tolerate as a function of cross-section slenderness, and (2) a strain hardening material model. These two components have been established for structural carbon steel and stainless steel in previous studies [1-5]. Building on recent proposals [9-12 and 1718], developments of a base curve, a suitable strain hardening material model and a global plastic analysis approach for aluminium alloy structures are described in the following sections. 


\subsection{Base curve}

The CSM base curve defines the limiting level of strain $\varepsilon_{c s m}$ that a cross-section can endure before failure. It was developed based on both stub column tests and four-point bending tests on carbon steel, stainless steel and aluminium alloys. Different cross-section types such as SHS/RHS, stiffened SHS/RHS, I-sections, angles and channels were all involved in the analyses.

In the CSM, the cross-section slenderness $\bar{\lambda}_{p}$ is defined in non-dimensional form as the square root of the ratio of the yield stress $f_{y}$ to the elastic buckling stress $\sigma_{c r}$ of the section (Equation (1)). The elastic buckling stress can be determined using approximate formulae [19] or numerical tools, such as CUFSM [20]. Both methods take into account the effects of element interaction instead of considering the slenderness of the most slender individual element only; in the present study, the programme CUFSM [20] was used.

$\bar{\lambda}_{p}=\sqrt{f_{y} / \sigma_{c r}}$

The cross-section deformation capacity $\varepsilon_{c s m} / \varepsilon_{y}$ for non-slender sections is defined in a normalised form as the strain at ultimate load $\varepsilon_{l b}$ minus $0.2 \%$ plastic strain, divided by the yield strain $\varepsilon_{y}$, where $\varepsilon_{y}=f_{y} / E$, with $E$ being the Young's modulus. For stub columns, the deformation capacity is determined with reference to the end shortening at the ultimate load $\delta_{u}$ (for sections reaching the yield load) or the ultimate load $P_{u}$ (for sections failing before reaching the yield load), as shown in Equations (2) and (3), respectively, where $L$ is the stub column length, $P_{y}=A f_{y}$ is the yield load and $P_{u}$ is the ultimate stub column capacity. Note that the transaction point between non-slender and slender sections $\left(\bar{\lambda}_{p} \leq 0.68\right)$ was identified in [5] and shown to be applicable to aluminium alloy sections in [9]. 


$$
\begin{array}{ll}
\frac{\varepsilon_{c s m}}{\varepsilon_{y}}=\frac{\varepsilon_{l b}-0.002}{\varepsilon_{y}}=\frac{\delta_{u} / L-0.002}{\varepsilon_{y}} & \text { for } P_{u} \geq P_{y} \text { and } \bar{\lambda}_{p} \leq 0.68 \\
\frac{\varepsilon_{c s m}}{\varepsilon_{y}}=\frac{P_{u}}{P_{y}} & \text { for } P_{u}<P_{y} \text { or } \bar{\lambda}_{p}>0.68
\end{array}
$$

In bending, under the assumption that plane sections remain plane and normal to the neutral axis, there is a linear relationship $(\varepsilon=\kappa y)$ between strain $\varepsilon$ and curvature $\kappa$, where $y$ is the distance from the neutral axis. The deformation capacity of a cross-section in bending is defined in a similar manner as for stub columns, using Equations (4) and (5), where $\kappa_{e l}$ is the curvature at yield, $\kappa_{u}$ is the curvature at ultimate load, $M_{u}$ is the ultimate bending capacity, $M_{e l}$ is the elastic moment capacity and $y_{c}$ is the distance from the neutral axis to the extreme compression fibre.

$$
\begin{array}{lr}
\frac{\varepsilon_{c s m}}{\varepsilon_{y}}=\frac{\varepsilon_{l b}-0.002}{\varepsilon_{y}}=\frac{\kappa_{u} y_{c}-0.002}{\kappa_{e l} y_{c}} & \text { for } M_{u} \geq M_{e l} \text { and } \bar{\lambda}_{p} \leq 0.68 \\
\frac{\varepsilon_{c s m}}{\varepsilon_{y}}=\frac{M_{u}}{M_{e l}} & \text { for } M_{u}<M_{e l} \text { or } \bar{\lambda}_{p}>0.68
\end{array}
$$

The first part of the base curve for non-slender sections of all metallic material is given by Equation (6). The two upper bounds to the CSM limiting strain $\varepsilon_{c s m}$ are $15 \varepsilon_{y}$ and $C_{l} \varepsilon_{u}$, where $C_{l}=0.5$ for aluminium alloys, which relate to limiting plastic deformations and avoiding over-predictions of strength using the simplified material model and material fracture, respectively. The data from stub column and four-point bending tests and simulations, which failed by material yielding and inelastic local buckling, are plotted in Figure 1 on a graph of deformation capacity versus cross-section slenderness, together with the base curve. This first part of the base curve, developed for carbon steel and stainless steel, 
may be seen to also provide a good prediction of deformation capacity for aluminium alloy cross-sections.

$$
\frac{\varepsilon_{c s m}}{\varepsilon_{y}}=\frac{0.25}{\bar{\lambda}_{p}^{3.6}} \text { but } \frac{\varepsilon_{c s m}}{\varepsilon_{y}} \leq \operatorname{lesser}\left(15, \frac{C_{1} \varepsilon_{u}}{\varepsilon_{y}}\right) \quad \text { for } \bar{\lambda}_{p} \leq 0.68
$$

The second part of the base curve is for slender sections of all metallic materials, as given in Equation (7). Since the strain ratios $\left(\varepsilon_{c s m} / \varepsilon_{y}\right)$ for slender sections are proportional to the load ratios $\left(P_{u} / P_{y}\right.$ and $\left.M_{u} / M_{e l}\right)$, the function of cross-section deformation capacity and cross-section slenderness takes the same form as the relationship between yield strength reduction and cross-section slenderness in strength based design methods, such as the direct strength method (DSM) [21] and effective width approach. For compatibility with the first part of the CSM base curve, this second part of the base curve for slender sections should also pass through the transition point $\bar{\lambda}_{p}=0.68$ at $\varepsilon_{c s m} / \varepsilon_{y}=1.0$. Thus, the second part of the CSM base curve was derived by modifying the coefficients of the existing strength functions to fit a collection of test data on carbon steel, stainless steel and aluminium alloy slender sections to give:

$$
\frac{\varepsilon_{c s m}}{\varepsilon_{y}}=\left(1-\frac{0.222}{\bar{\lambda}_{p}^{1.05}}\right) \frac{1}{\bar{\lambda}_{p}^{1.05}} \quad \text { for } \quad \bar{\lambda}_{p}>0.68
$$

\subsection{Material model}

The CSM employs an elastic-linear hardening material model, with a strain hardening modulus $E_{s h}$ varying with material grade. The slope of the linear hardening region is defined on the basis of a line passing through two fixed points: the first point is the $0.2 \%$ proof stress 
$f_{y}$ and the corresponding strain at $\varepsilon_{y}+0.002$, and the second point is the ultimate tensile stress $f_{u}$ and a proportion $C_{2}$ of the ultimate strain plus $0.2 \%$ strain (i.e. $C_{2} \varepsilon_{u}+0.002$ ). The choice of $C_{2} \varepsilon_{u}$ is described in Section 2.3.2, while the addition of the $0.2 \%$ strain to the second point during the derivation of the model allows the curve to be shifted back by $0.2 \%$ strain, with no change in the slope, such that the final model passes through the points $\left(\varepsilon_{y}, f_{y}\right)$ and $\left(C_{2} \varepsilon_{u}, f_{u}\right)$. The development of this material model and the choice of parameters are described in the following sub-sections.

\subsubsection{Ultimate strain prediction}

The strain at the ultimate tensile stress $\varepsilon_{u}$ is a key factor in the CSM material model, particularly in determining the slope of the strain hardening region. However, in most cases, this value is not reported by manufacturers and thus it is not readily available to designers. EC9 [8] provides formulae to predict the strain corresponding to the ultimate tensile stress of the material $\varepsilon_{u}$, as given in Equations (8) and (9). A comparison between the EC9 [8] predictive model and collected data for $\varepsilon_{u}[9,15,22$ and 23] is shown in Figure 2. The experimental values of ultimate strain $\varepsilon_{u, t e s t}$ may be seen to be generally lower than the predicted values $\varepsilon_{u, p r e d}$, from EC9 [8] with large scatter. In the present study, a new expression (Equation (10)) is proposed for the predictions of ultimate strain. It follows a similar format to the ultimate strain prediction equation for stainless steel in EC3 Part 1.4 [24]; the model coefficients $\left(C_{3}=0.13\right)$ and $\left.C_{4}=0.059\right)$ were calibrated based on tensile coupon test results by means of least squares regression. Note that no data with $f_{u} / f_{y} \leq 1.01$ was used in the development of Equation (10); this may therefore be considered as the limit of applicability of Equation (10). The predictions improve significantly for the ultimate strain as shown in Figure 2. 


$$
\begin{array}{ll}
\varepsilon_{u}=0.3-0.22\left(f_{y} / 400\right) & \text { for } f_{y}<400 \mathrm{~N} / \mathrm{mm}^{2} \\
\varepsilon_{u}=0.08 & \text { for } f_{y} \geq 400 \mathrm{~N} / \mathrm{mm}^{2} \\
\varepsilon_{u}=C_{3}\left(1-f_{y} / f_{u}\right)+C_{4} &
\end{array}
$$

\subsubsection{Strain hardening slope}

The CSM bi-linear material model contains two parts: the initial elastic part and the linear hardening part (Figure 3). The elastic part is defined by the Young's Modulus of the material $E$. The strain hardening region has a strain hardening slope $E_{s h}$, which is defined by Equation (11). A suitable expression for defining $E_{s h}$ was initially explored by considering two end points at $\left(\varepsilon_{y}+0.002, f_{y}\right)$ and $\left(C_{2} \varepsilon_{u}+0.002, f_{u}\right)$, where $C_{2}$ is the proportion of ultimate strain. With $0.2 \%$ plastic strain deduced from both end points, the resulting material model passes through the points $\left(\varepsilon_{y}, f_{y}\right)$ and $\left(C_{2} \varepsilon_{u}, f_{u}\right)$. The value of $C_{2}$ was determined from experimental data [9 and 15] with two considerations. The first consideration was to obtain an accurate fit to measured $\sigma-\varepsilon$ curves; this was achieved through least squares regression. The second was to ensure that the simplified model did not over-predict any experimental $\sigma-\varepsilon$ curves to a significant degree. A value of $C_{2}=0.5$ was found to satisfy both considerations, with a maximum over-prediction in stress $\Delta d$ of less than $5 \%$ when compared to the collected set of 33 measured aluminium alloy $\sigma-\varepsilon$ curves [ 4 and 9]. Note that lower values of $C_{2}$ provided an improved least squares fit to the collected test data but higher maximum over-predictions, while the opposite was found for higher values of $C_{2}$. In addition to providing a suitably accurate representation of experimental data, the value of $C_{2}=0.5$ also matches that given in Annex E of EC9 [8]. The proposed CSM material model is therefore consistent with this 
existing provision. A typical comparison between a measured $\sigma-\varepsilon$ curve and the CSM material model is shown in Figure 3.

$$
E_{s h}=\frac{f_{u}-f_{y}}{C_{2} \varepsilon_{u}-\varepsilon_{y}}
$$

\subsection{Global plastic analysis (moment redistribution)}

The CSM for indeterminate structures is an extension of the CSM for determinate structures, and provides allowance for plastic moment redistribution. In addition to considering nonlinear material characteristics at the cross-sectional level, the CSM for indeterminate structures [4] employs concepts from traditional plastic design - global plastic analysis. However, the CSM considers the degree of rotation at each plastic hinge, leading to different cross-section capacities at different hinges. The maximum moment resisted by each crosssection is based on a strain that is proportional to the required hinge rotation. The critical plastic hinge is first identified as the one with the highest hinge rotation demand, and this hinge is assigned its full CSM cross-section moment capacity. The moments at subsequent hinges are determined based on the hinge rotational demand ratios [4].

\subsection{Summary of design procedures}

\subsubsection{General}

For all cross-sections to be designed, whether under compression or bending, the limiting strain is determined from the base curve given by Equations (6) for $\bar{\lambda}_{p} \leqslant 0.68$ and Equation (7) for $\bar{\lambda}_{p}>0.68$, where $\bar{\lambda}_{p}$ is calculated from Equation (1). 


\subsubsection{Cross-section compression resistance}

Cross-section compression resistance $P_{c s m}$ is subsequently determined from Equation (12) for $\bar{\lambda}_{p} \leqslant 0.68$ and Equation (13) for $\bar{\lambda}_{p}>0.68$, with $E_{s h}$ from Equation (11)

$$
P_{c s m}=A f_{c s m} \quad \text { for } \bar{\lambda}_{p} \leqslant 0.68
$$

where $f_{c s m}=f_{y}+E_{s h} \varepsilon_{y}\left(\frac{\varepsilon_{c s m}}{\varepsilon_{y}}-1\right)$

$$
P_{c s m}=\frac{\varepsilon_{c s m}}{\varepsilon_{y}} A f_{y} \quad \text { for } \quad \bar{\lambda}_{p}>0.68
$$

Figure 4 presents the results of stub column tests on square hollow sections (SHS), rectangular hollow sections (RHS), channels and angles, where the test ultimate loads are normalised by the yield limit $A f_{y}$. The comparisons clearly show capacities in excess of the yield load $P_{y}\left(=A f_{y}\right)$ for the non-slender sections $\left(\bar{\lambda}_{p} \leqslant 0.68\right)$ and hence the benefit to be derived from strain hardening.

\subsubsection{Cross-section bending resistance}

Cross-section resistance in bending is determined from Equation (14) for $\bar{\lambda}_{p} \leqslant 0.68$ and Equation (15) for $\bar{\lambda}_{p}>0.68$, with $\alpha=2$ for SHS and RHS, as well as I-sections in major axis bending and $\alpha=1.2$ for I-sections in minor axis bending.

$$
M_{c s m}=W_{p l} f_{y}\left[1+\frac{E_{s h}}{E} \frac{W_{e l}}{W_{p l}}\left(\frac{\varepsilon_{c s m}}{\varepsilon_{y}}-1\right)-\left(1-\frac{W_{e l}}{W_{p l}}\right) /\left(\frac{\varepsilon_{c s m}}{\varepsilon_{y}}\right)^{\alpha}\right] \quad \text { for } \quad \bar{\lambda}_{p} \leqslant 0.68
$$




$$
M_{c s m}=\frac{\varepsilon_{c s m}}{\varepsilon_{y}} M_{e l} \quad \text { for } \bar{\lambda}_{p}>0.68
$$

Figure 5 shows the results of simply supported bending tests on SHS/RHS and I-sections, where the ultimate moments are normalised by the elastic moment capacity $M_{e l}=W_{e l} f_{y}$, with $W_{e l}$ being the elastic section modulus. The benefits of spread of plasticity and strain hardening may be clearly seen for non-slender sections $\left(\bar{\lambda}_{p} \leqslant 0.68\right)$.

\subsubsection{Indeterminate structures}

In the case of indeterminate structures, such as continuous beams, benefit can also be derived from strain hardening. Figure 6 shows experimental and numerical ultimate loads $F_{u}$ for beams in five-point bending (i.e. two-span continuous beams with a point load in each span) normalized by the plastic collapse load $F_{\text {coll }}$. This theoretical load level required to form a plastic collapse mechanism is calculated on the basis of the formation and subsequent rotation of plastic hinges at their plastic moment capacity $W_{p l} f_{y}$. Figure 6 shows that a number of specimens with semi-compact or even slender sections can achieve ultimate loads close to the theoretical plastic collapse load $F_{\text {coll }}$, while the plastic or compact sections exhibit capacities that are generally well beyond this load level.

The CSM enables collapse loads beyond those determined from traditional plastic design through a systematic exploitation of strain hardening $[12,13]$. The CSM design procedure for indeterminate structures is summarised as follows:

(1) Identify the location of the plastic hinges, of number i, in a manner similar to traditional plastic design and determine the respective hinge rotations $\theta_{i}$; 
(2) Calculate the cross-section slenderness $\bar{\lambda}_{p}$ at each hinge position according to Equation (1);

(3) Determine the level of strain that a cross-section can endure $\left(\varepsilon_{c s m}\right)$ from the base curve at each hinge according to Equations (6) and (7);

(4) For a given hinge rotation $\theta_{i}$, section height $H_{i}$ and strain ratio $\left(\varepsilon_{c s m} / \varepsilon_{y}\right)_{i}$, calculate the corresponding hinge demands $\alpha_{i}$ :

$$
\alpha_{i}=\frac{\theta_{i} H_{i}}{\left(\varepsilon_{c s m} / \varepsilon_{y}\right)_{i}}
$$

The critical hinge is identified as the one with the highest hinge demand $\alpha_{\max }=\max \left\{\alpha_{i}\right\}$, with the strain ratio at the critical hinge now labelled $\left(\varepsilon_{c s m} / \varepsilon_{y}\right)_{\max }$.

(5) The final strain ratios at each hinge location $\left(\varepsilon_{c s m} / \varepsilon_{y}\right)_{h i n g e, i}$ are then assigned in proportion to the hinge rotation ratios:

$$
\left(\frac{\varepsilon_{c s m}}{\varepsilon_{y}}\right)_{\text {hinge }, i}=\frac{\alpha_{i}}{\alpha_{\max }}\left(\frac{\varepsilon_{c s m}}{\varepsilon_{y}}\right)_{\max } \text { but }\left(\frac{\varepsilon_{c s m}}{\varepsilon_{y}}\right)_{\text {hinge }, i} \leq\left(\frac{\varepsilon_{c s m}}{\varepsilon_{y}}\right)_{i}
$$

(6) Calculate the cross-section bending moment capacity $M_{i}$ at each plastic hinge based on the corresponding strain ratio $\left(\varepsilon_{c s m} / \varepsilon_{y}\right)_{h i n g e, i}$, according to Equations (14) and (15).

(7) Determine the collapse load of the system by means of virtual work, whereby the external work done by the applied loads $F_{j}$ acting through virtual displacements $\delta_{j}$ is equated to that of the internal work resulting from the hinge rotations $\theta_{i}$.

$$
\sum_{j} F_{j} \delta_{j}=\sum_{i} M_{i} \theta_{i}
$$


Note that if $\left(\varepsilon_{c s m} / \varepsilon_{y}\right)_{\max }$ derived from step (4) is less than 3.6 for SHS/RHS, global plastic analysis (Steps (5) - (7)) is not recommended [4] and elastic global analysis should be used.

\section{Comparisons between test/numerical results and design resistance predictions}

Ultimate capacities from experiments and numerical simulations on aluminium alloy stub columns $\left(P_{u}\right)$, simply supported beams $\left(M_{u}\right)$ and continuous beams $\left(F_{u}\right)$ have been compared with the predictions of the Aluminium Design Manual [6] $\left(P_{A A}, M_{A A}\right.$ and $\left.F_{A A}\right)$, the Australia/New Zealand Standards [7] $\left(P_{A S / N Z S}, M_{A S / N Z S}\right.$ and $\left.F_{A S / N Z S}\right)$, Eurocode 9 [8] ( $P_{E C 9}$, $M_{E C 9}$ and $\left.F_{E C 9}\right)$ and the continuous strength method [9, 10 and 12] $\left(P_{c s m}, M_{c s m}\right.$ and $\left.F_{c s m}\right)$. The comparisons were performed using the measured material properties and geometries of the sections with all safety factors set to unity. Figures 7-11 present the comparisons between test results and design predictions, while Tables 1-5 summarise the comparative results of all available data (i.e. experimental and numerical).

\subsection{Stub columns}

Test data on aluminium alloy stub columns from the literature [9, 14-16, 22 and 25-29] are compared with the compressive strengths predicted by the different design methods [6-9]. A total of 346 experiments have been considered, with a range of cross-section types: 110 SHS/RHS, 203 plain channel sections and 33 angle sections - see Table 1 and Figure 7.

The mean values of experimental and numerical-to-predicted ultimate loads for the AA Standard $\left(P_{u} / P_{A A}\right)$ and the AS/NZS Standard $\left(P_{u} / P_{A S / N Z S}\right)$ are 1.19 and 1.28 with the corresponding coefficients of variation $(\mathrm{COV})$ of 0.251 and 0.250 , respectively. All comparisons made herein with EC9 use the more favourable Annex F approach, which utilizes the ultimate tensile stress $f_{u}$ for Class 1 sections. The comparisons between the EC9 
predictions and the experimental (and numerical) results $P_{u} / P_{E C 9}$ yield a mean value of 1.16 and a COV of 0.169. Unlike the AA and AS/NZS standards, EC9 often overestimates the strength of slender sections. The CSM yields more accurate predictions with the mean value of 1.06 and COV of 0.100 , which is an improvement over the aforementioned three international design specifications.

\subsection{Simply supported beams}

In this section, the ultimate bending resistances obtained from tests and numerical simulations collected from the literature [10, 13, 23 and 30-32], are compared with the nominal flexural design strengths predicted by the three international specifications [6-8] and the CSM for aluminium structures [10], as shown in Tables 2-3 and Figures 8-9. Note that the comparisons made with EC9 use the more favourable Annex F approach to enable greater capacities for Class 1 sections by taking account of strain hardening.

Comparisons between the experimental results on simply supported beams (of SHS/RHS and I-sections) and the four design methods are shown in Figure 8, while a summary of the comparisons with a total of 212 experimental and numerical data is presented in Table 2. The AS/NZS [7] generally underestimated the capacity of the simply supported beams by approximately $40 \%$ with a large scatter (mean value of $M_{u} / M_{A S / N Z S}=1.39$ and COV=0.212). The AA [6] and EC9 [8] specifications provide better predictions, with mean values of 1.27 and 1.21 and corresponding COVs of 0.187 and 0.109 for the experimental and numerical-to-predicted moment ratios $M_{u} / M_{A A}$ and $M_{u} / M_{E C 9}$, respectively. The CSM approach (mean value of $M_{u} / M_{c s m}=1.15$ and $\mathrm{COV}=0.114$ ) provides a more accurate prediction of the bending capacity, with up to approximately $25 \%$ improvement compared to the AS/NZS predictions. 
Similar comparisons were also performed on 71 simply supported beams of SHS/RHS with internal cross stiffeners (Table 3 and Figure 9). Although the performance of the CSM for SHS/RHS with internal stiffeners is not as accurate compared with the predictions for hollow sections without internal stiffeners, the CSM still has the mean value of $M_{u} / M_{c s m}$ closer to unity (1.18) than other methods and shares the similar minimum COV value with EC9 $(\mathrm{COV}=0.153)$. Consistently, predictions of the AA and AS/NZS specifications are overly conservative (mean value of $M_{u} / M_{A A}=1.40$ and $M_{u} / M_{A S / N Z S}=1.66$ ) and rather scattered $\left(\mathrm{COV}\right.$ of $M_{u} / M_{A A}=0.207$ and $\mathrm{COV}$ of $\left.M_{u} / M_{A S / N Z S}=0.233\right)$.

\subsection{Continuous beams}

In this section, the aforementioned design methods [6-8 and 12] are used to predict the ultimate capacities of a series of five-point bending specimens [11-13], and hence to assess the accuracy of the design rules for indeterminate aluminium alloy structures. The comparative results are summarized in Tables $4-5$ and plotted in Figures $10-11$. The different codified treatments for specimens in various cross-section classes are detailed in $\mathrm{Su}$ et al. [12]. The plastic hinge method in Annex H of EC9 [8] is employed herein to obtain more favourable predictions.

By assessing the presented comparative results in Table 4 and Figure 10 for 147 continuous beams of SHS/RHS, it may be seen that the AS/NZS [7] is the most conservative design specification (mean value of $F_{u} / F_{A S / N Z S}=1.88, \mathrm{COV}=0.275$ ), followed by the AA Standard [6] (mean value of $F_{u} / F_{A A}=1.71$ and $\mathrm{COV}=0.256$ ). The plastic hinge method in Annex H of EC9 [8] may be seen to be more accurate than the other two specifications, with a mean value of $F_{u} / F_{E C 9}=1.42$ and $\mathrm{COV}=0.203$. The CSM for indeterminate structures [12] is the most accurate design approach, with the mean experimental and numerical-to-predicted 
value being closest to unity (mean value of $F_{u} / F_{c s m}=1.34$ ) and the lowest $\mathrm{COV}=0.163$ showing the least scatter.

Table 5 and Figure 11 illustrate the accuracy of the different design methods for 109 SHS/RHS continuous beams with internal cross stiffeners. Similar to the comparative results for hollow sections, the AS/NZS [7] is again the most conservative and scattered compared to the other design approaches (mean value of $F_{u} / F_{A S / N Z S}=2.02, \mathrm{COV}=0.276$ ), while the AA [6] offers improved results with a mean value of $F_{u} / F_{A A}=1.70$ and $\mathrm{COV}=0.251$. The performance of EC9 [8] (mean value of $F_{u} / F_{E C 9}=1.37$ and $\mathrm{COV}=0.178$ ) and the CSM (mean value of $\left.F_{u} / F_{c s m}=1.25, \mathrm{COV}=0.165\right)$ are more similar, though the CSM is again more accurate.

\subsection{Discussion}

The relative accuracies of the predictions from the four considered methods relate primarily to: (1) the utilization of strain hardening and (2) allowance for moment redistribution. The AA [6] and AS/NZS [7] methods consider neither of these effects, while EC9 and the CSM allow for both, though the improved accuracy of the CSM is attributed to the more rational and consistent deformation-based approach.

\section{Reliability analyses}

The purpose of the statistical analyses performed in this section is to validate the reliability level of the existing design methods and the recently developed continuous strength method (CSM) for the design of aluminium alloy stub columns [9], simply supported beams [10] and continuous beams [12]. Two different analysis approaches - set out by AISC [33] and in EN 1990 [34] - are outlined and utilised in the present study. 


\subsection{AISC approach}

The reliability analysis approach set out by AISC [33] uses the reliability index $\beta$ as an indicator of the design safety level. The calculation procedure adopted herein is detailed in [33], while the reliability parameters and criteria for aluminium alloy structural members are taken from Clause 1.3.2 of Appendix 1, Part I of the AA Design Manual [6]. The target reliability index for aluminium alloy columns is 2.50 according to the AA [6] requirement. In the present study, the same criterion is also applied to EC9 [8]. Thus, if the calculated reliability index is greater than or equal to 2.50 , the design method is deemed to be reliable. The mean values and COVs for material properties $\left(M_{m}\right.$ and $\left.V_{M}\right)$ and fabrication variables $\left(F_{m}\right.$ and $V_{F}$ ) are specified [6] as: $M_{m}=1.10$ (for behaviour governed by the yield stress) and 1.00 (for behaviour governed by the ultimate stress), $F_{m}=1.00, V_{M}=0.06$ and $V_{F}=0.05$. Thus, $M_{m}$ was taken equal to 1.10 when evaluating the AA and AS/NZS design provisions, but was taken as 1.00 for Class 1 sections and 1.10 for Classes 2, 3 and 4 sections when assessing EC9. For the CSM, the appropriate value of $M_{m}$ was determined for each specimen, based on the corresponding CSM limiting stress $f_{c s m}$. The statistical parameters $P_{m}$ and $V_{p}$ are the mean value and $\mathrm{COV}$ of the experimental (or numerical)-to-predicted load ratios, as presented in Tables 1-5. The correction factor $C_{P}$ given in [6] is used to account for the influence of the size of the data pool. The considered design specifications (i.e. the AA, the AS/NZS and EC9) use different load combinations and resistance factors in the determination of the reliability index $\beta$. For aluminium alloy beams, the AA [6] specification uses a resistance factor $\phi$ of 0.90 and a load combination of 1.2DL + 1.6LL (where DL and LL signify Dead loads and Live loads, respectively), the AS/NZS [7] specification uses a resistance factor $\phi$ of 0.85 and a load combination of 1.25DL $+1.50 \mathrm{LL}$, while EC9 [8] effectively employs a resistance factor $\phi$ of $0.91(\approx 1 / 1.1)$ and a load combination of 1.35DL + 1.50LL. 


\subsection{EN 1990 approach}

In EN 1990 [34], the partial safety factor $\gamma_{M O}$ is generally taken as the indicator of the design safety level for cross-section resistance. The target partial factor $\gamma_{M 0}$ is recommended to be 1.10 in Clause 6.1.3 in EC9 [8]. A calculated partial safety factor that is lower than 1.10 indicates that a higher degree of reliability exists than that required by EN 1990 for a design formulation. Annex D of EN 1990 provides a set of application rules for carrying out standard statistical evaluations, a review of which has been prepared by Afshan et al [35]. The values of statistical parameters adopted in the analyses were taken as those recommended in the Aluminum Design Manual [6], namely the material over-strength $M_{m}$ (between 1.00 to 1.10$)$ and the coefficients of variation of yield strength $V_{M}(0.06)$ and geometric properties $V_{F}(0.05)$.

\subsection{Results}

The AISC [33] and EN 1990 [34] provide two commonly used reliability analysis approaches. The aforementioned design methods [6-10 and 12] were evaluated using both two approaches herein. The key results are presented in Tables 1- 5 and discussed in this section.

\subsubsection{Stub columns}

The reliability indices $\beta$ were found to be $2.32,2.61,2.54$ and 2.60 for the AA [6], AS/NZS [7], EC9 [8] and the CSM [9, 10 and 12], respectively, as shown in Table 1. The AS/NZS, EC9 and the CSM have exceeded the target value of $\beta=2.50$ and can therefore be deemed as reliable for aluminium alloy stub column design, while the AA provisions fall marginally below the target value. 
Following the EN 1990 reliability approach, the obtained partial factors $\gamma_{M 0}$ were found to be greater than 1.10 for all design methods, as shown in Table 1, and thus fail to meet the specified requirements. The calculated partial factor $\gamma_{M 0}$ for the $\operatorname{CSM}\left(\gamma_{M 0}=1.38\right)$ is smaller than the calculated values for the three existing design approaches, and may therefore be considered, on the basis of historical precedent, to be a safe design method for aluminium alloy cross-section in compression.

\subsubsection{Simply supported beams}

Considering simply supported beams with hollow cross-sections, the reliability index $\beta$ of the CSM was found to be 2.79 according to the AISC approach, as shown in Table 2, and may therefore be deemed reliable. Meanwhile, the CSM partial factor $\gamma_{{ }_{0}}$ obtained from EN 1990 was 1.27, which is smaller than the values obtained for the AA and equal to the AS/NZS methods, but larger than the value obtained for the EC9 provisions of 1.16 and larger than the target value of 1.10 .

Considering simply supported beams with hollow cross-sections and internal stiffeners, the reliability index $\beta$ is 2.63 for the CSM, as shown in Table 3, which is greater than 2.50 and thus the CSM was found to be reliable according to the AISC approach. However, the calculated value of $\gamma_{M 0}$ for the CSM was 1.49 , which is substantially greater than 1.10 , as were the corresponding values for the other design methods.

\subsubsection{Continuous beams}

For the continuous beams, the results of the reliability analyses are shown in Tables 4 and 5 for the hollow and cross-stiffened sections respectively. For both cases, the target reliability index of $\beta=2.50$ is met for all four design methods according to the AISC method, but all fail 
to meet the EN 1990 requirements, with required values of $\gamma_{M 0}$ ranging between 1.23 and 1.45 .

\subsection{Concluding remarks}

To conclude, the three specifications [6-8] and the CSM [9, 10 and 12] generally satisfy the reliability requirement of $\beta>2.50$, using the AISC approach [33], but generally fail to meet the EN 1990 [34] requirements of $\gamma_{M 0}=1.10$. Since the CSM yields similar required values of $\gamma_{M 0}$ to EC9, it may be argued, on the basis of historical precedent, that the design proposals are safe. Further assessment of the differing reliability bases of the AISC approach and EN 1990 is recommended for future work.

\section{Calculation examples}

Two examples are outlined in this section to demonstrate the calculation procedures of the CSM for the design of aluminium alloy stub columns and continuous beams. Both examples use non-slender hollow sections, produced by extrusion (with sharp corners) from a heattreated 6061-T6 aluminium alloy. The geometric and material properties of two tested specimens have been chosen to demonstrate the design approach and all factors of safety have been set to unity, to allow direct comparison with the test results $[9,11]$.

\subsection{Example 1. Stub column resistance}

The CSM predicted capacity of the RHS $\mathrm{H} 70 \times 55 \times 4.2 \mathrm{C}$ (where $\mathrm{H}$ refers to high strength, $\mathrm{C}$ denotes compression and the dimensions relate to nominal cross-section height, width and thickness, respectively) stub column tested in [9], is determined as follows: 
Cross-section dimensions and material properties:

\begin{tabular}{|c|c|c|}
\hline$H=69.9 \mathrm{~mm}$ & $B=54.9 \mathrm{~mm}$ & $A=951.9 \mathrm{~mm}^{2}$ \\
\hline$E=65 \mathrm{GPa}$ & $f_{y}=193 \mathrm{MPa}$ & $f_{u}=207 \mathrm{MPa}$ \\
\hline$\varepsilon_{u}=0.13(1-19$ & $+0.059=0.068$ & $\varepsilon_{y}=193 / 65000=0.003$ \\
\hline
\end{tabular}

Step 1: Determine cross-section slenderness

$f_{y}=193 \mathrm{MPa}, \sigma_{c r}=1489 \mathrm{MPa}$ from CUFSM [19]

Hence, $\bar{\lambda}_{p}=\sqrt{f_{y} / \sigma_{c r}}=\sqrt{193 / 1489}=0.36$

Step 2: Determine the cross-section deformation capacity

$$
\frac{\varepsilon_{c s m}}{\varepsilon_{y}}=\frac{0.25}{\bar{\lambda}_{p}^{3.6}}=\frac{0.25}{0.36^{3.6}}=10.28\left(\leq \operatorname{lesser}\left(15, \frac{0.5 \varepsilon_{u}}{\varepsilon_{y}}=11.67\right)\right)
$$

Step 3: Determine the strain hardening slope

$$
E_{s h}=\frac{f_{u}-f_{y}}{0.5 \varepsilon_{u^{-}} \varepsilon_{y}}=\frac{207-193}{0.5 \times 0.068-0.003}=437.5 \mathrm{MPa}
$$

Step 4: Determine the limiting CSM stress and predicted ultimate capacity

$$
\begin{aligned}
& f_{c s m}=f_{y}+E_{s h}\left(\varepsilon_{c s m}-\varepsilon_{y}\right)=193+437.5 \times(10.28-1) \times 0.003=205.2 \mathrm{MPa} \\
& P_{c s m}=A f_{c s m}=951.9 \times 205.2=195.3 \mathrm{kN}
\end{aligned}
$$

$($ Test ultimate load $=196.2 \mathrm{kN})$

\subsection{Example 2. Continuous beam resistance}

The CSM predicted capacity for the SHS H55×70×4.2B5II-R (where B5II denotes five-point bending in loading configuration II, explained below, and R signifies that this was a repeated test) continuous beam tested in [11], is determined as follows: 
Cross-section dimensions and material properties:

\begin{tabular}{lccc}
\hline$H=54.9 \mathrm{~mm}$ & $B=69.9 \mathrm{~mm}$ & $t=4.09 \mathrm{~mm}$ & $A=949.8 \mathrm{~mm}^{2}$ \\
$W_{e l}=18441 \mathrm{~mm}^{3}$ & $W_{p l}=22471 \mathrm{~mm}^{3}$ & $E=70 \mathrm{GPa}$ & $f_{y}=261 \mathrm{MPa}$ \\
$f_{u}=282 \mathrm{MPa}$ & $M_{p l}=5.855 \mathrm{kNm}$ & $\varepsilon_{u}=0.13(1-261 / 282)+0.059=0.069$ \\
$\varepsilon_{y}=261 / 70000=0.004 \quad$ Loading configuration II with $L_{l}=536 \mathrm{~mm}$ and $L_{2}=268 \mathrm{~mm}$
\end{tabular}

Step 1: Identify the location of the plastic hinges and determine hinge rotation (refer to Figure 12)

$L_{1}=2 L_{2}$

$\theta_{1=2} \delta / L_{2}=4 \delta / L_{1}$

$\theta_{2}=\delta / L_{1}+\delta / L_{2}=3 \delta / L_{1}$

Step 2: Determine cross-section slenderness

$f_{y}=261 \mathrm{MPa}, \sigma_{c r}=2131 \mathrm{MPa}$ from CUFSM [20]

Hence, $\bar{\lambda}_{p}=\sqrt{f_{y} / \sigma_{c r}}=\sqrt{261 / 2131}=0.35$

Step 3: Determine the cross-section deformation capacity

$$
\begin{aligned}
& \frac{\varepsilon_{c s m}}{\varepsilon_{y}}=\frac{0.25}{\bar{\lambda}_{p}^{3.6}}=\frac{0.25}{0.35^{3.6}}=10.95\left(>\text { lesser }\left(15, \frac{0.5 \varepsilon_{u}}{\varepsilon_{y}}=9.22\right)\right) \\
& \therefore \frac{\varepsilon_{c s m}}{\varepsilon_{y}}=9.22
\end{aligned}
$$

Step 4: Determine the strain hardening slope

$$
E_{s h}=\frac{f_{u}-f_{y}}{0.5 \varepsilon_{u}-\varepsilon_{y}}=\frac{282-261}{0.5 \times 0.069-0.004}=693.1 \mathrm{MPa}
$$

Step 5: Determine the corresponding hinge demands

The beam is of the same cross-section throughout its length, therefore: 


$$
\begin{aligned}
& \alpha_{1}=\frac{\theta_{1} H_{1}}{\left(\varepsilon_{c s m} / \varepsilon_{y}\right)_{1}}=\frac{\theta_{1} H}{\varepsilon_{c s m} / \varepsilon_{y}} \\
& \alpha_{2}=\frac{\theta_{2} H_{2}}{\left(\varepsilon_{c s m} / \varepsilon_{y}\right)_{2}}=\frac{\theta_{2} H}{\varepsilon_{c s m} / \varepsilon_{y}}=\frac{3}{4} \frac{\theta_{1} H}{\varepsilon_{c s m} / \varepsilon_{y}} \\
& \alpha_{\text {max }}=\alpha_{1} \\
& \left(\frac{\varepsilon_{c s m}}{\varepsilon_{y}}\right)_{\max }=\frac{\varepsilon_{c s m}}{\varepsilon_{y}}
\end{aligned}
$$

$\therefore$ Hinge1 is the critical hinge.

Step 6: Determine the cross-section deformation capacity at each hinge position

$$
\begin{aligned}
& \left(\frac{\varepsilon_{c s m}}{\varepsilon_{y}}\right)_{\text {hinge }, 1}=\frac{\alpha_{1}}{\alpha_{\max }}\left(\frac{\varepsilon_{c s m}}{\varepsilon_{y}}\right)_{\max }=\frac{\varepsilon_{c s m}}{\varepsilon_{y}}=9.22 \\
& \left(\frac{\varepsilon_{c s m}}{\varepsilon_{y}}\right)_{\text {hinge }, 2}=\frac{\alpha_{2}}{\alpha_{\max }}\left(\frac{\varepsilon_{c s m}}{\varepsilon_{y}}\right)_{\max }=\frac{3}{4} \frac{\varepsilon_{c s m}}{\varepsilon_{y}}=6.92
\end{aligned}
$$

Step 7: Determine the cross-section capacity at each hinge

$$
\begin{aligned}
\left(\frac{M_{c s m}}{M_{p l}}\right)_{1} & =\left(1+\frac{E_{s h}}{E} \frac{W_{e l}}{W_{p l}}\left(\frac{\varepsilon_{c s m}}{\varepsilon_{y}}-1\right)-\left(1-\frac{W_{e l}}{W_{p l}}\right)\left(\frac{\varepsilon_{c s m}}{\varepsilon_{y}}\right)^{-2}\right)_{1} \\
& =1+\frac{693.1}{70000} \frac{18441}{22471}(9.22-1)-\left(1-\frac{18441}{22471}\right)(9.22)^{-2} \\
& =1.06
\end{aligned}
$$$$
\left(M_{c s m}\right)_{1}=1.06 \times 5.855=6.234 \mathrm{kNm}
$$

$$
\begin{aligned}
\left(\frac{M_{c s m}}{M_{p l}}\right)_{2} & =\left(1+\frac{E_{s h}}{E} \frac{W_{e l}}{W_{p l}}\left(\frac{\varepsilon_{c s m}}{\varepsilon_{y}}-1\right)-\left(1-\frac{W_{e l}}{W_{p l}}\right)\left(\frac{\varepsilon_{c s m}}{\varepsilon_{y}}\right)^{-2}\right)_{2} \\
& =1+\frac{693.1}{70000} \frac{18441}{22471}(6.92-1)-\left(1-\frac{18441}{22471}\right)(6.92)^{-2} \\
& =1.04
\end{aligned}
$$

$\left(M_{c s m}\right)_{2}=1.04 \times 5.855=6.115 \mathrm{kNm}$

Step 8: Determine total applied collapse load 


$$
\begin{aligned}
2 F \delta & =M_{1} \theta_{1}+2 M_{2} \theta_{2} \\
& =4 M_{1} \delta / L_{1}+6 M_{2} \delta / L_{1} \\
2 F & =4 M_{1} / L_{1}+6 M_{1} / L_{1} \\
& =4 \times 6.234 / 536+6 \times 6.115 / 536 \\
& =114.9 \mathrm{kN}
\end{aligned}
$$

(Test ultimate load $=130.6 \mathrm{kN})$

\section{Conclusions}

The significance of strain hardening and moment redistribution on the behaviour and design of aluminium alloy structures was explored in this paper. A new deformation-based design approach, termed the continuous strength (CSM), was described, extended and assessed. The two key components of the CSM, which are the base curve that defines the maximum strain that a cross-section can endure and a bi-linear material model, were examined in detail. The base curve was also extended to cover slender cross-sections, enabling the exploitation of strain hardening in some non-doubly symmetric slender sections, which can experience high strains on the tensile side. The CSM has been evaluated against approximately 900 experimental and numerical results, including aluminium alloy stub columns, simply supported beams and continuous beams. Cross-section shapes considered in the present study include square and rectangular hollow sections, both with and without internal cross stiffeners, I-sections, angles and channels. It was shown that the CSM offers more accurate mean resistance predictions and less scatter for both determinate and indeterminate aluminium alloy structures compared to the Aluminum Design Manual [6], Australian/New Zealand Standard [7] and Eurocode 9 [8]. The improved resistance functions of the CSM enable more efficient design and a more consistent representation of the true structural response. Reliability analyses were also performed on the three existing code provisions and 
the CSM. All were deemed to satisfy the AISC reliability targets but fall short of the EN 1990 requirements.

\section{Acknowledgement}

The research work described in this paper was supported by a grant from The University of Hong Kong under the seed funding programme for basic research.

\section{NOTATION}

$A \quad=$ Cross-sectional area

$B \quad=$ Section width

$C_{1} \quad=$ Coefficient to define a 'cut off' strain to avoid over-predictions of material strength

$C_{2} \quad=$ Coefficient to define the strain hardening slope

$C_{3}$ and $C_{4} \quad=$ Coefficients used in the predictive expression for ultimate strain

$C_{P} \quad=$ Correction factor

$E \quad=$ Young's modulus

$E_{s h} \quad=$ Strain hardening modulus

$f_{c s m} \quad=$ CSM limiting stress

$f_{y} \quad=$ Yield strength, taken as the $0.2 \%$ proof strength

$f_{u} \quad=$ Ultimate tensile strength

$F_{A A} \quad=$ Ultimate load of continuous beams predicted by the AA

$F_{A S / N Z S}=$ Ultimate load of continuous beams predicted by the AS/NZS

$F_{\text {coll }} \quad=$ Ultimate load level at which a plastic collapse mechanism forms (with crosssectional capacity at the plastic hinges equal to $W_{p} f_{y}$ ) 


$$
\begin{aligned}
& F_{c s m} \quad=\text { Ultimate load of continuous beams predicted by the CSM } \\
& F_{\text {design }} \quad=\text { Design load of continuous beams } \\
& F_{E C 9} \quad=\text { Ultimate load of continuous beams predicted by the plastic hinge method in } \\
& \text { Annex H of EC9 } \\
& F_{\text {exp }} \quad=\text { Experimental ultimate load of continuous beams } \\
& F_{m} \quad=\text { Mean value of fabrication factor } \\
& F_{u} \quad=\text { Experimental and numerical ultimate load for continuous beams } \\
& H \quad \text { = Section Height for SHS/RHS } \\
& L \quad=\text { Member length } \\
& M_{A A} \quad=\text { Ultimate moment of simply supported beams predicted by the AA } \\
& M_{A S / N Z S}=\text { Ultimate moment of simply supported beams predicted by the AS/NZS } \\
& M_{c s m} \quad=\text { Ultimate moment of simply supported beams predicted by the CSM } \\
& M_{\text {design }} \quad \text { = Design moment capacity of simply supported beams } \\
& M_{E C 9} \quad=\text { Ultimate moment of simply supported beams predicted by Annex F of EC9 } \\
& M_{e l} \quad=W_{e l} f_{y} \text { is the elastic moment capacity } \\
& M_{\text {exp }} \quad=\text { Experimental ultimate moment of simply supported beams } \\
& M_{m} \quad=\text { Material over-strength } \\
& M_{p l} \quad=W_{p l} f_{y} \text { is the plastic moment capacity } \\
& M_{u} \quad=\text { Experimental and numerical ultimate moment of simply supported beams } \\
& P_{A A} \quad=\text { Ultimate load of stub columns predicted by AA } \\
& P_{A S / N Z S}=\text { Ultimate load of stub columns predicted by AS/NZS } \\
& P_{c s m} \quad=\text { Ultimate load of stub columns predicted by the CSM } \\
& P_{E C 9}=\text { Ultimate load of stub columns predicted by Annex F of EC9 } \\
& P_{m} \quad=\text { Mean value of test-to-predicted load ratios } \\
& P_{y} \quad=A f_{y} \text { is the yield load of stub columns } \\
& P_{u} \quad=\text { Experimental and numerical ultimate load of stub columns }
\end{aligned}
$$




\begin{tabular}{|c|c|}
\hline$t$ & $=\mathrm{Wall}$ thickness \\
\hline$V_{F}$ & $=$ Coefficient of variation of fabrication factor \\
\hline$V_{M}$ & $=$ Coefficient of variation of material factor \\
\hline$V_{P}$ & $=$ Coefficient of variation of test-to-predicted load ratios \\
\hline$W_{e l}$ & $=$ Elastic section modulus \\
\hline$W_{p l}$ & $=$ Plastic section modulus \\
\hline$x$ & $=$ Proportion of ultimate strain \\
\hline$y$ & $=$ Distance to the neutral axis \\
\hline$y_{c}$ & $=$ Distance between extreme compressive fibre and the neutral axis \\
\hline$\beta$ & $=$ Reliability index \\
\hline$\delta$ & $=$ Displacement at hinge point \\
\hline$\delta_{u}$ & $=$ End shortening at ultimate load \\
\hline$\varepsilon$ & $=$ Strain \\
\hline$\varepsilon_{c s m}$ & $=\mathrm{CSM}$ limiting strain \\
\hline$\varepsilon_{l b}$ & $\begin{array}{l}=\text { Local buckling strain, equal to stub column end shortening divided by stub } \\
\text { column length at ultimate load }\end{array}$ \\
\hline$\varepsilon_{u}$ & $=$ Strain at ultimate tensile stress \\
\hline$\varepsilon_{y}$ & $=f_{y} / E$ is the yield strain \\
\hline$\gamma_{M O}$ & $=$ Partial safety factor \\
\hline$\kappa$ & $=$ Curvature \\
\hline$\kappa_{e l}$ & $=$ Curvature at yield \\
\hline$\kappa_{u}$ & $=$ Curvature at ultimate load \\
\hline$\phi$ & $=$ Resistance factor \\
\hline $\bar{\lambda}_{p}$ & $=$ Cross-section/plate slenderness \\
\hline$\theta$ & $=$ Rotation at plastic hinge \\
\hline
\end{tabular}




$$
\begin{array}{ll}
\alpha & =\text { Hinge rotation demand } \\
\sigma & =\text { Stress } \\
\sigma_{c r} & =\text { Elastic buckling stress } \\
\Delta d & =\text { difference in stress }
\end{array}
$$

\section{References}

[1] Gardner, L. (2008) “The continuous strength method”, Proceedings of ICE - Structures and Building, 161 (3), 127-133.

[2] Gardner, L., Wang, F. and Liew, A. (2011) "Influence of strain hardening on the behavior and design of steel structures", International Journal of Structural Stability and Dynamics, $11(5), 855-875$.

[3] Afshan, S. and Gardner, L. (2013) "The continuous strength method for structural stainless steel design” Thin-Walled Structures, 68(2013): 42-49

[4] Buchanan, C., Gardner, L. and Liew, A. (2016), "The continuous strength method for the design of circular hollow sections”, Journal of Constructional Steel Research, 118: 207-216.

[5] Liew, A. and Gardner, L., (2015), "Ultimate capacity of structural steel cross-sections under compression bending and combined loading", Structures, 1: 2-11.

[6] Aluminum Association (AA) (2010). Aluminum Design Manual. Washington, D.C, US.

[7] Australian/New Zealand Standard (AS/NZS). (1997). "Aluminum structures part 1: Limit state design.” AS/NZS 1664.1:1997, Sydney, Australia.

[8] European Committee for Standardization (EC9) (2007). "Eurocode 9: Design of aluminium structures-Part 1-1: General rules-General rules and rules for buildings." BS EN 1999-1-1:2007, CEN. 
[9] Su, M., Young, B. and Gardner, L. (2014) “Testing and design of aluminum alloy crosssections in compression.” Journal of Structural Engineering, ASCE, 140(9), 04014047.

[10] Su, M., Young, B. and Gardner, L. (2014), "Deformation-based design of aluminium alloy beams" Engineering Structures, 80: 339-349.

[11] Su, M., Young, B. and Gardner, L. (2015), "Continuous beams of aluminum alloy tubular cross-section - part I: tests and model validation", Journal of Structural Engineering, ASCE, 141(9), 04014232.

[12] Su, M., Young, B. and Gardner, L. (2015), “Continuous beams of aluminum alloy tubular cross-section - part II: parametric study and design", Journal of Structural Engineering, ASCE, 141(9), 04014233.

[13] Su, M., Young, B. and Gardner, L., "Flexural resistance of aluminium alloy SHS and RHS with internal cross stiffeners", Engineering Structures, in press.

[14] Mennink, J. (2002) Cross-Sectional Stability of Aluminum Extrusions: Prediction of the Actual Local Buckling Behavior. PhD Thesis, The Netherlands.

[15] Zhu, J.H., and Young, B. (2006). "Tests and design of aluminum alloy compression members.” Journal of Structural Engineering, ASCE 132(7), 1096-1107.

[16] Zhu, J.H. and Young, B. (2008). "Behavior and design of aluminum alloy structural members.” Advanced Steel Construction 4(2), 158-172.

[17] Ashraf, M. and Young, B. (2011). "Design formulations for non-welded and welded aluminium stub columns using Continuous Strength Method.” Engineering Structures. 33(12), 3197-3207

[18] Gardner, L. and Ashraf, M. (2006) "Structural design for non-linear metallic materials", Engineering Structures 28(6), 926-934.

[19] Seif, M. and Schafer, B.M. (2010). "Local buckling of structural steel shapes", Journal of Constructional Steel Research, 66 (10), 1232-1247. 
[20] Li, Z. and Schafer, B.M. (2010) "Buckling analysis of cold-formed steel members with general boundary conditions using CUFSM: conventional and constrained finite strip methods." Proceedings of the 20th International Specification Conference on Cold-Formed Steel Structures. pp. 17-31 (St. Louis, MO., 2010).

[21] Schafer B.W. and Peköz T. Direct strength prediction of cold-formed steel members using numerical elastic buckling solutions. In: Proceedings of the 14th international specialty conference on cold-formed steel structures, University of Missouri-Rolla, Rolla, Mo 1998. pp. 69-76.

[22] Langseth, M. and Hopperstad, O.S. (1997) "Local buckling of square thin-walled aluminium extrusions", Thin- Walled Structures. 27(1), 117-126.

[23] Moen, L.A., Hopperstad, O.S. and Langseth, M. (1999) "Rotational capacity of aluminium beams under moment gradient. I: experiments”, Journal of Structural Engineering, ASCE 125(8), 910-920

[24] European Committee for Standardization (EC3). (2006) "Eurocode 3: Design of steel structures-Part 1-4: General rules - Supplementary rules for stainless steels”. EN 1993-14:2006, CEN.

[25] Bijlaard, P. P. and Fisher, G. P. (1953). "Column strength of H-sections and square tubes in post buckling range of component plates" National Advisory Committee for Aeronautics Technical Note 2994, Washington.

[26] Mazzolani, F.M., Faella, C., Piluso, V. and Rizzano, G. (1998). "Local buckling of aluminium members: experimental analysis and cross-sectional classification.” Department of Civil Engineering, University of Salerno, Italy

[27] Landolfo, R., Piluso, V., Langseth, M. and Hopperstad, O.S. (1999). “EC9 provisions for flat internal elements: comparison with experimental results." Light-Weight Steel and Aluminum Structures, pp. 515-522. 
[28] Hassinen, P. (2000). "Compression strength of aluminum columns - Experimental and numerical studies." Proceedings of the 3rd International Conference on Coupled Instabilities of Metal Structures, 241-248, CIMS'2000, ICP, London, UK.

[29] Mazzolani, F.M., Piluso, V., and Rizzano, G. (2011), "Local buckling of aluminum alloy angles under uniform compression." Journal of Structural Engineering, ASCE 137(2), 173184.

[30] Lai, Y.F.W. and Nethercot, D.A. (1992). "Strength of aluminium members containing local transverse welds" Engineering Structures 14(4), 241-254

[31] Zhu, J.H. and Young, B. (2009). "Design of aluminum alloy flexural members using direct strength method.” Journal of Structural Engineering, ASCE 135(5), 558-566.

[32] Zhu, J.H. and Young, B. (2006). "Experimental investigation of aluminum alloy thinwalled tubular members in combined compression and bending." Journal of Structural Engineering, ASCE 132(12), 1955-1966.

[33] American Institute of Steel Construction (AISC) Commentary (2005). Commentary on the specification for structural steel buildings, AISC 360, Chicago, IL.

[34] European Committee for Standardization (EN 1990) (2002). "Eurocode: Basis of Structural Design.” EN 1990-2002, CEN.

[35] Afshan, S., Francis, P., Baddoo, N.R. and Gardner, L. (2015), "Reliability analysis of structural stainless steel design provisions", Journal of Constructional Steel Research, 114: 293-304. 
Table 1.Comparison of results and reliability analyses for stub columns (346 data points)

\begin{tabular}{lrrrrr} 
& \multicolumn{1}{c}{$P_{u}$} & \multicolumn{1}{c}{$P_{u}$} & & $P_{u}$ & \multicolumn{1}{c}{$P_{u}$} \\
\cline { 3 - 4 } & $P_{A A}$ & $P_{A S / N Z S}$ & & $P_{E C 9}$ & $P_{c s m}$ \\
\hline Mean, $P_{m}$ & 1.19 & 1.28 & 1.17 & 1.06 \\
COV, $V_{p}$ & 0.251 & 0.250 & & 0.169 & 0.100 \\
$\phi$ & 0.90 & 0.85 & 0.91 & 0.90 \\
$\beta$ & 2.32 & 2.61 & 2.54 & 2.60 \\
$\gamma_{M 0}$ & 1.60 & 1.52 & 1.51 & 1.38 \\
\hline
\end{tabular}

Table 2. Comparison of results and reliability analyses for simply supported beams (212 data points)

\begin{tabular}{|c|c|c|c|c|}
\hline & $\frac{M_{u}}{M_{A A}}$ & $\frac{M_{u}}{M_{A S / N Z S}}$ & $\frac{M_{u}}{M_{E C 9}}$ & $\frac{M_{u}}{M_{c s m}}$ \\
\hline Mean, $P_{m}$ & 1.27 & 1.39 & 1.21 & 1.15 \\
\hline $\mathrm{COV}, V_{p}$ & 0.187 & 0.212 & 0.109 & 0.125 \\
\hline$\phi$ & 0.90 & 0.85 & 0.91 & 0.90 \\
\hline$\beta$ & 2.88 & 3.09 & 2.92 & 2.79 \\
\hline$\gamma_{M 0}$ & 1.31 & 1.27 & 1.16 & 1.27 \\
\hline
\end{tabular}

Table 3. Comparison of results and reliability analyses for simply supported beams on SHS/RHS with internal cross stiffeners (71 data points)

\begin{tabular}{|c|c|c|c|c|}
\hline & $\frac{M_{u}}{M_{A A}}$ & $\frac{M_{u}}{M_{A S / N Z S}}$ & $\frac{M_{u}}{M_{E C 9}}$ & $\frac{M_{u}}{M_{c s m}}$ \\
\hline Mean, $P_{m}$ & 1.40 & 1.66 & 1.27 & 1.18 \\
\hline $\mathrm{COV}, V_{p}$ & 0.207 & 0.233 & 0.150 & 0.153 \\
\hline$\phi$ & 0.90 & 0.85 & 0.91 & 0.90 \\
\hline$\beta$ & 3.07 & 3.47 & 2.65 & 2.63 \\
\hline$\gamma_{M O}$ & 1.48 & 1.38 & 1.42 & 1.49 \\
\hline
\end{tabular}


Table 4. Comparison of results and reliability analyses for continuous beams on SHS/RHS (147 data points)

\begin{tabular}{|c|c|c|c|c|}
\hline & $\frac{F_{u}}{F_{A A}}$ & $\frac{F_{u}}{F_{A S / N Z S}}$ & $\frac{F_{u}}{F_{E C 9}}$ & $\frac{F_{u}}{F_{c s m}}$ \\
\hline Mean, $P_{m}$ & 1.71 & 1.88 & 1.42 & 1.34 \\
\hline $\mathrm{COV}, V_{p}$ & 0.256 & 0.275 & 0.203 & 0.163 \\
\hline$\phi$ & 0.90 & 0.85 & 0.91 & 0.90 \\
\hline$\beta$ & 3.34 & 3.53 & 2.91 & 3.13 \\
\hline$\gamma_{M 0}$ & 1.36 & 1.32 & 1.45 & 1.38 \\
\hline
\end{tabular}

Table 5. Comparison of results and reliability analyses for continuous beams on SHS/RHS with internal cross stiffeners (109 data points)

\begin{tabular}{|c|c|c|c|c|}
\hline & $\frac{F_{u}}{F_{A A}}$ & $\frac{F_{u}}{F_{A S / N Z S}}$ & $\frac{F_{u}}{F_{E C 9}}$ & $\frac{F_{u}}{F_{c s m}}$ \\
\hline Mean, $P_{m}$ & 1.70 & 2.02 & 1.37 & 1.25 \\
\hline $\mathrm{COV}, V_{p}$ & 0.251 & 0.276 & 0.178 & 0.165 \\
\hline$\phi$ & 0.90 & 0.85 & 0.91 & 0.90 \\
\hline$\beta$ & 3.34 & 3.70 & 2.88 & 2.79 \\
\hline$\gamma_{M 0}$ & 1.33 & 1.23 & 1.37 & 1.43 \\
\hline
\end{tabular}




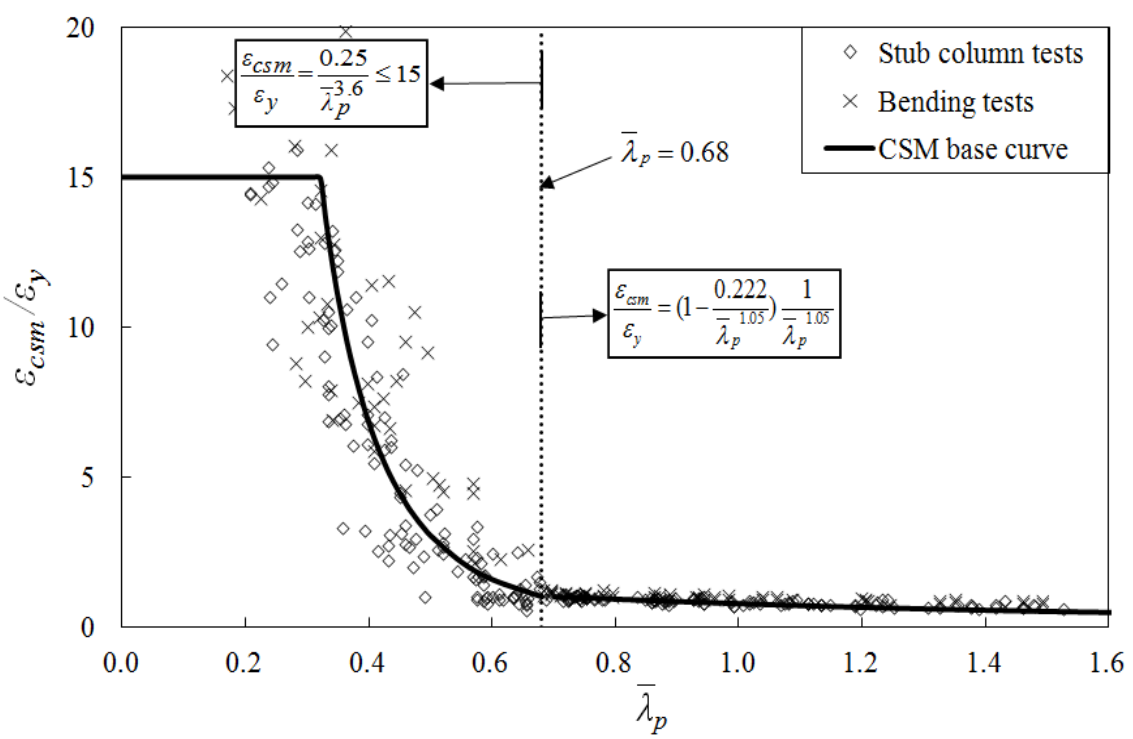

Figure 1: Base curve - relationship between strain ratio and cross-section slenderness

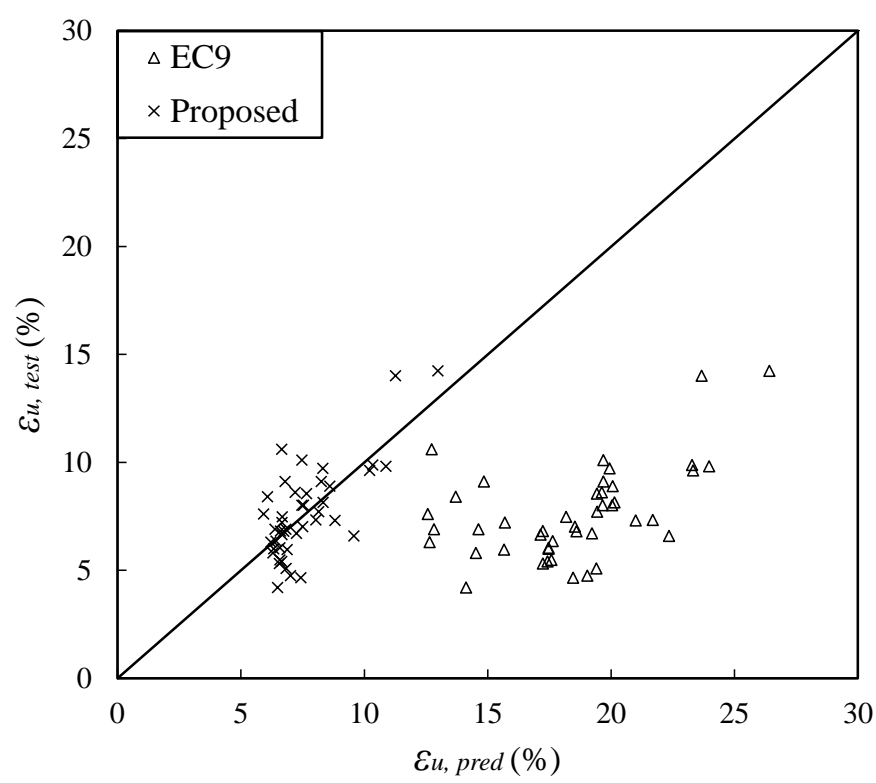

Figure 2: Test versus predicted material ultimate strain 


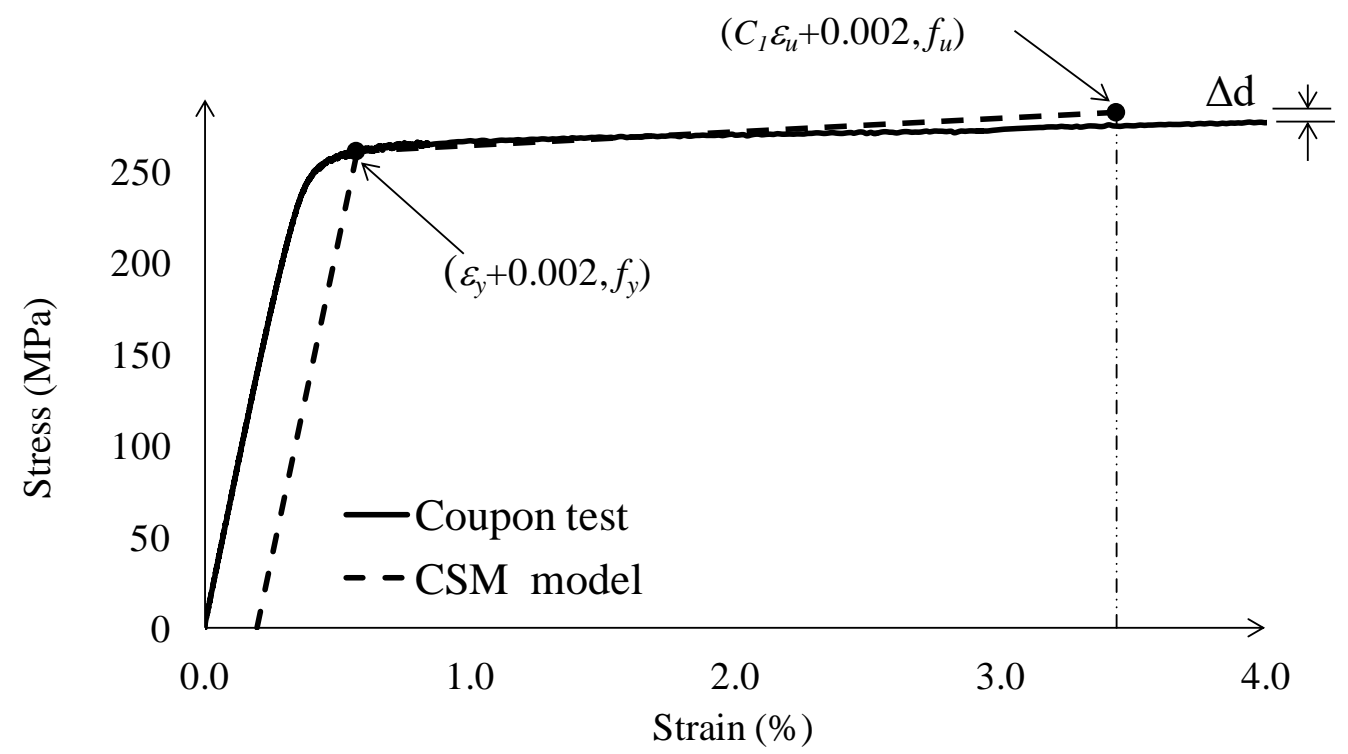

Figure 3: Typical measured stress-strain curve and the bi-linear model.

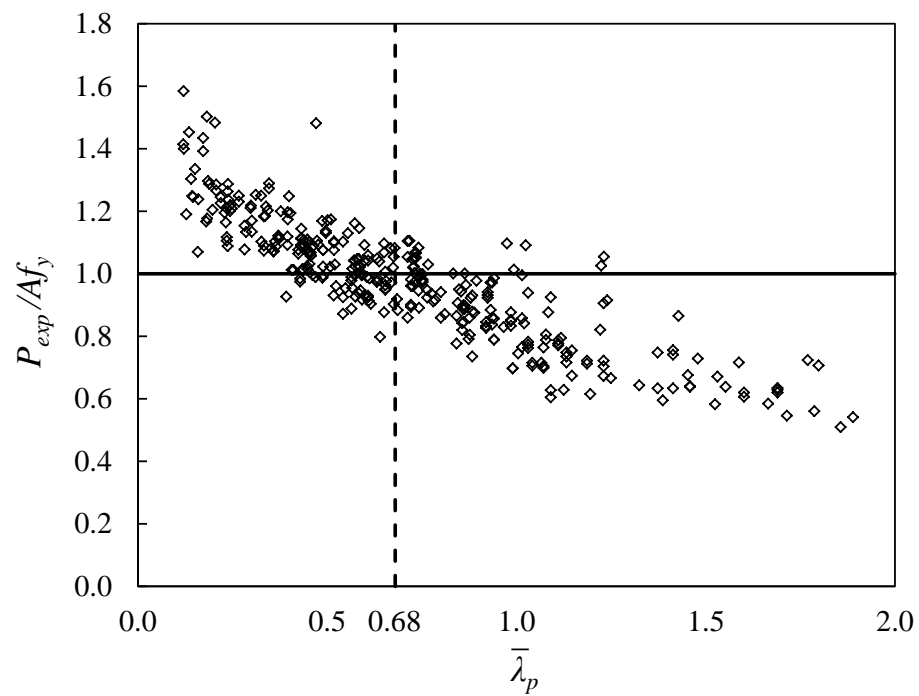

Figure 4: Comparison of 346 stub column test results with yield load. 


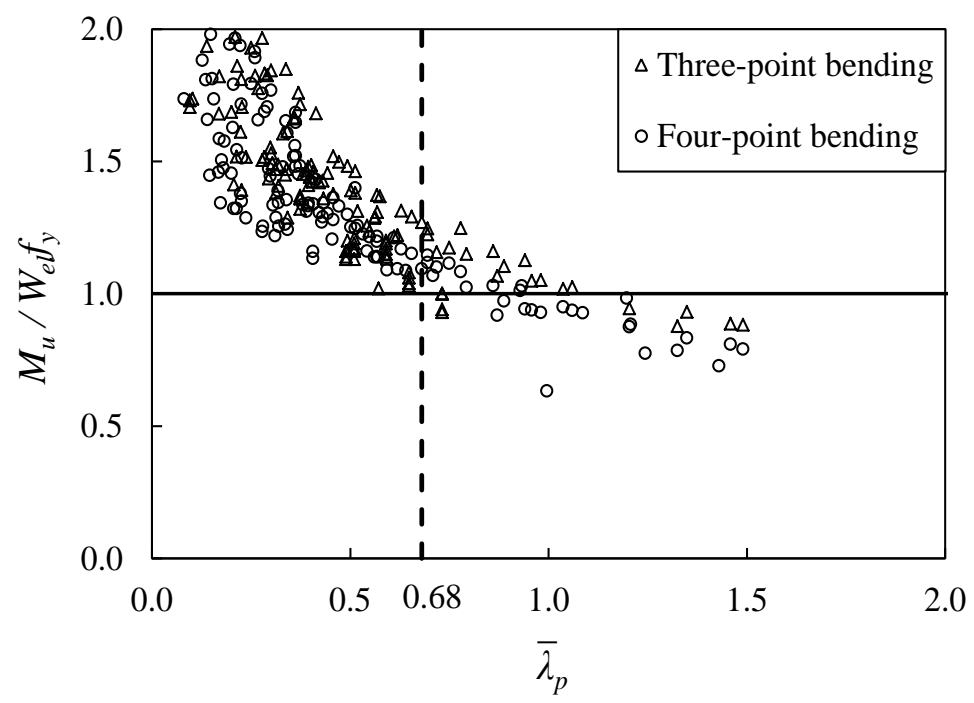

Figure 5: Comparison of 275 simply supported bending experimental and numerical results with yield moment.

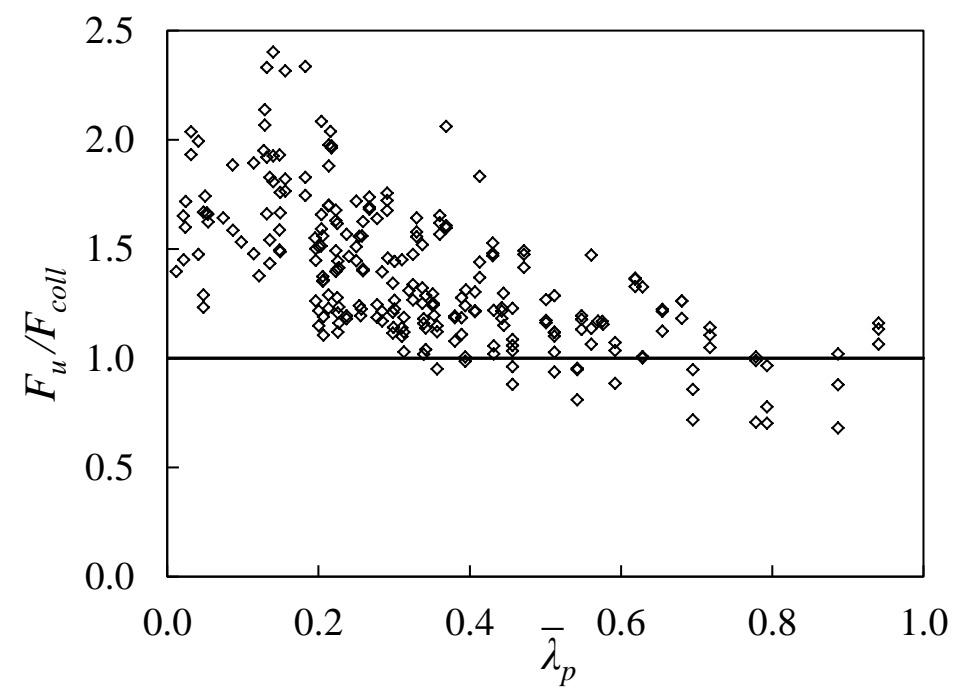

Figure 6. Comparison of 256 five-point bending experimental and numerical results with theoretical plastic collapse loads 


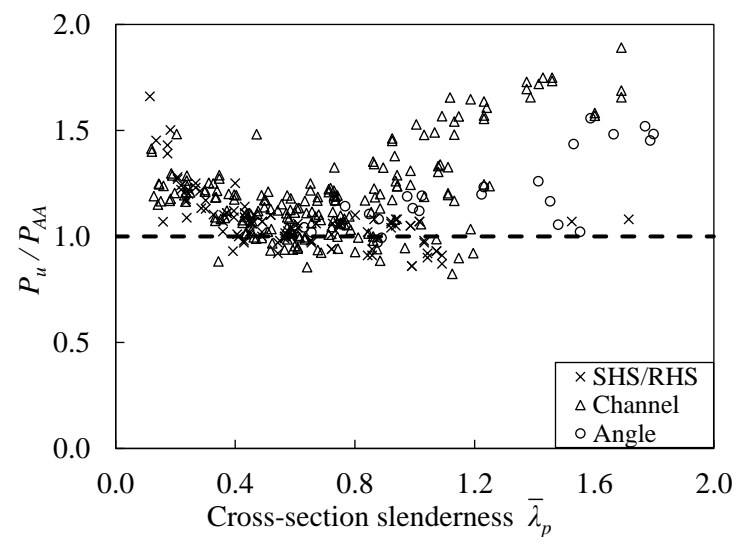

(a)

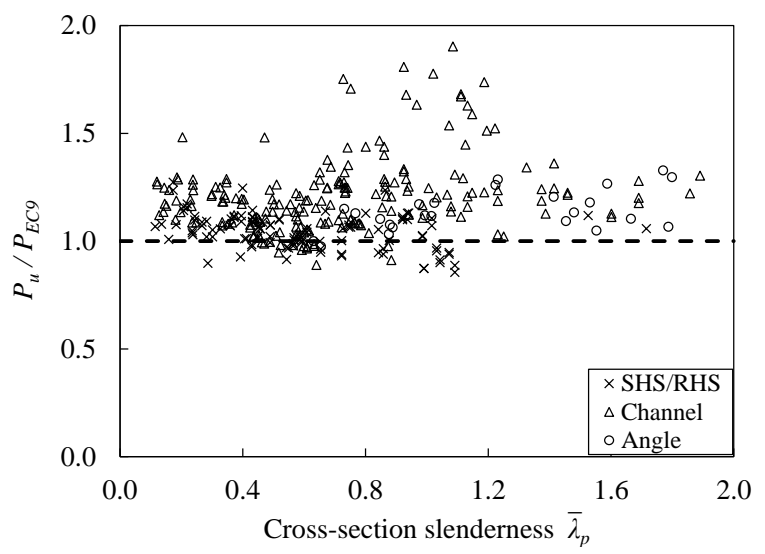

(c)

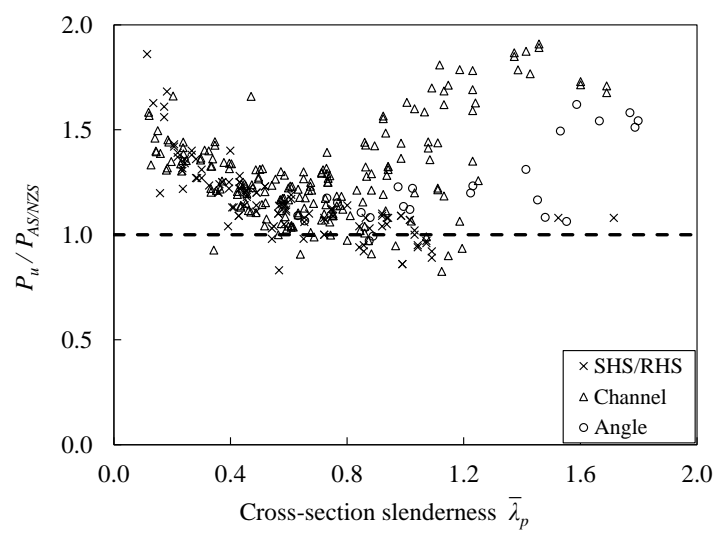

(b)

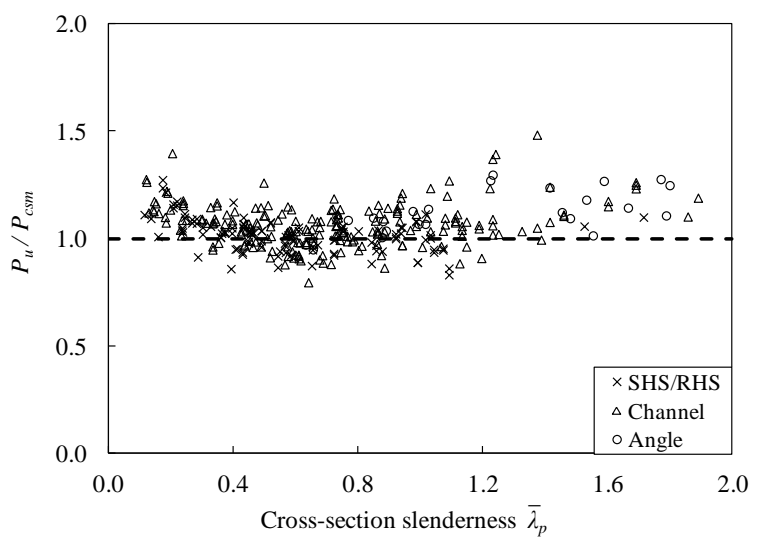

(d)

Figure 7: Comparison of stub column test results with (a) AA [5], (b) AS/NZS [6], (3) EC9 [7] and (4) the CSM design methods 


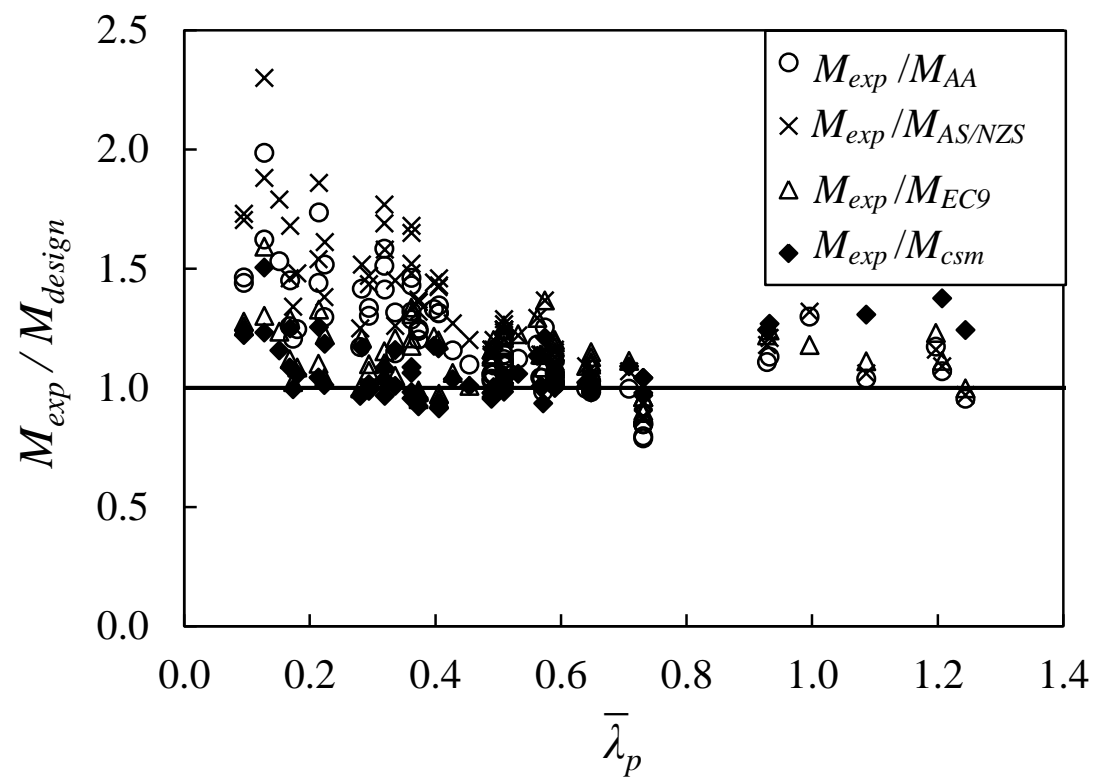

Figure 8: Comparison of simply supported bending test results (of SHS/RHS and I-sections) with the AA, AS/NZS, EC9 and the CSM approaches

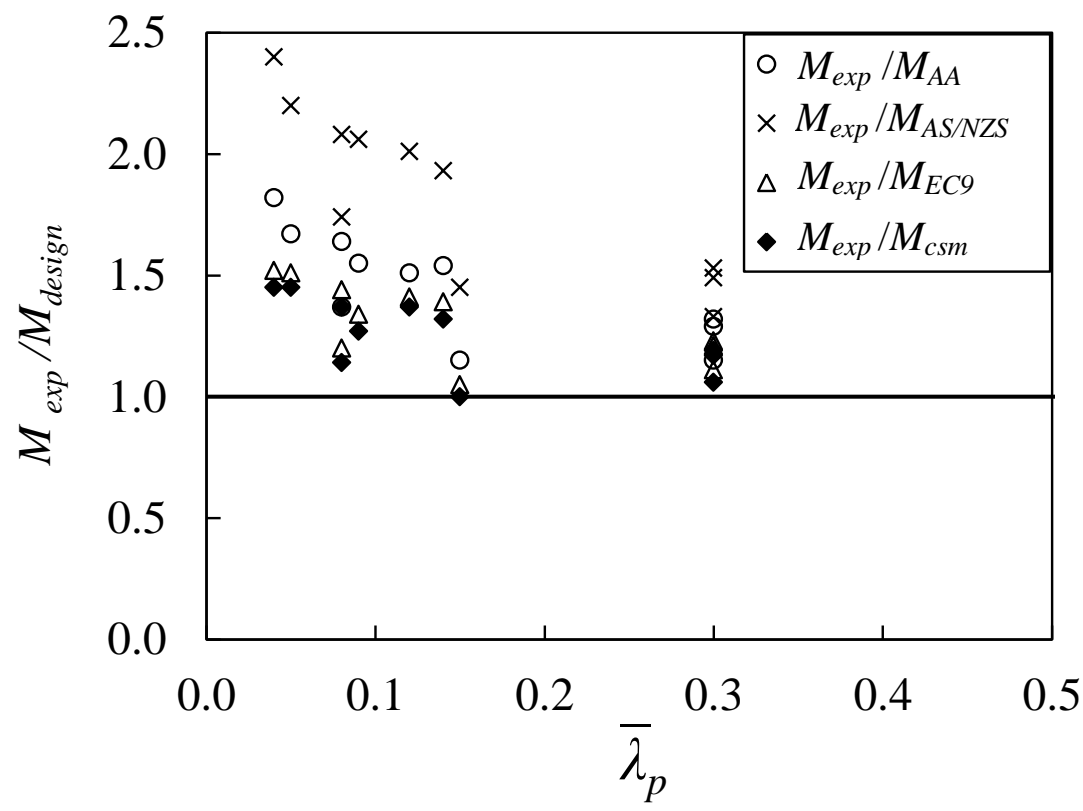

Figure 9: Comparison of simply supported bending test results (of SHS/RHS with internal stiffeners) with the AA, AS/NZS, EC9 and the CSM approaches 


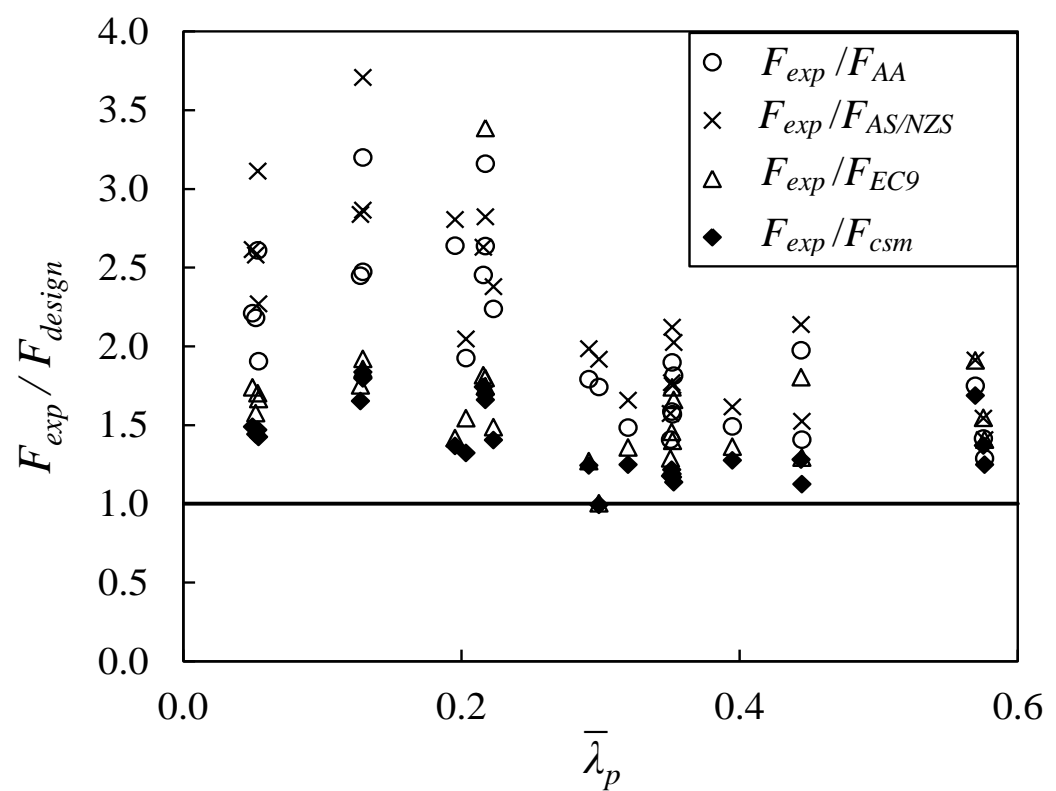

Figure 10: Comparison of continuous bending test results (of SHS/RHS) with the AA, AS/NZS, EC9 and the CSM approaches

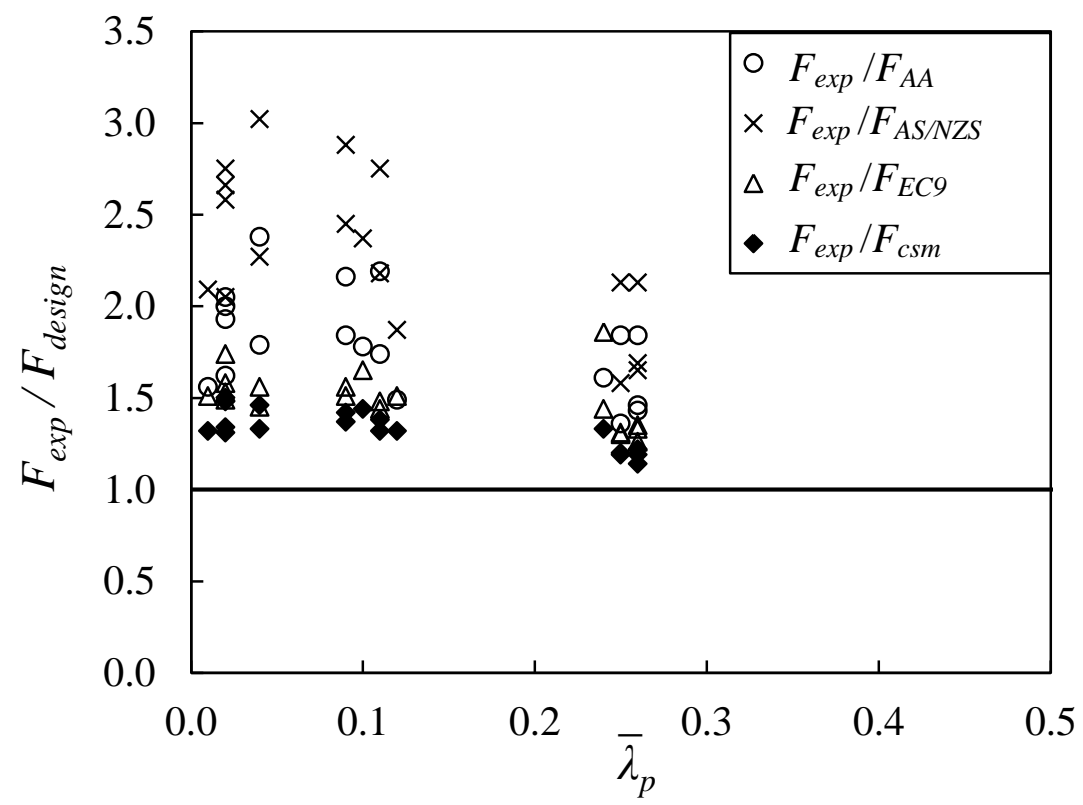

Figure 11: Comparison of continuous bending test results (of SHS/RHS with internal stiffeners) with the AA, AS/NZS, EC9 and the CSM approaches 


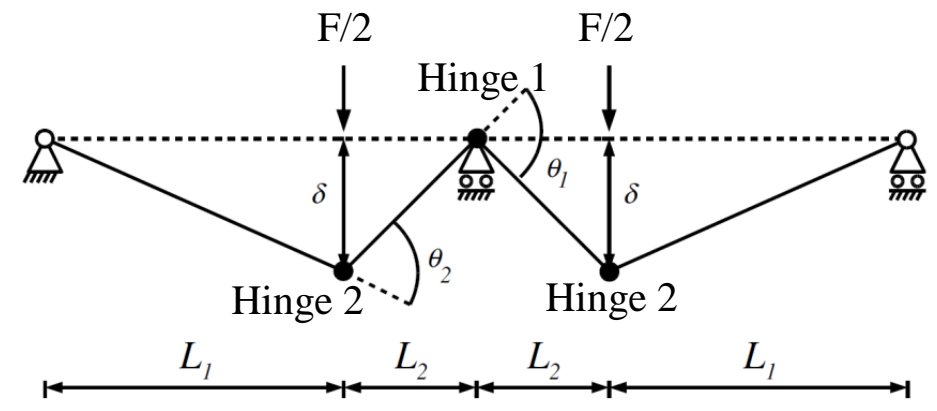

Figure 12: Plastic collapse mechanism for two-span continuous beam 